\title{
Macrogeographic patterns of breeding system diversity in the Daphnia pulex group. I. Breeding systems of Canadian populations
}

\author{
PAUL D. N. HEBERT, STEVEN S. SCHWARTZ*, ROBERT D. WARD† \& \\ TERRIE L. FINSTON \\ Department of Zoology, University of Guelph, Guelph, Ontario N1G 2W1, Canada *Department of Biology, Berry \\ College, Rome, Georgia 30149, U.S.A. and tDivision of Fisheries, CSIRO, Hobart, Tasmania 7001
}

\begin{abstract}
Efforts to deduce the evolutionary significance of sexual reproduction from the taxonomic and ecological distributions of asexuals rely on the presumption that reversions of asexual taxa to sexual reproduction are rare. There is growing evidence, however, that reversions may be likely as long as asexuals are diploid, and some sexual populations persist. However, few systems have been studied in sufficient detail to provide insight into the nature of interactions between the sexual and asexual components of a single taxon. The cladoceran crustaceans Daphnia pulex and D. pulicaria both show variation in breeding system with some populations reproducing by cyclic and others by obligate parthenogenesis. The present study used allozymic analysis to characterize the breeding systems of both species across Canada. Although $F_{1}$ hybrids were prevalent between the species and invariably reproduced by obligate parthenogenesis, each parent species showed regional variation in its breeding system. $D$. pulex reproduces by obligate parthenogenesis in eastern Canada but switches to cyclic parthenogenesis in the west with an abrupt transition coincident with the forest/prairie ecotone. $D$. pulicaria shows a divergent pattern, with populations on the priaries reproducing by obligate parthenogenesis, while those in eastern Canada and the far west are cyclic parthenogens. The results make clear that breeding systems in both taxa tend to be uniform over large areas. The discordance in breeding system employed by each species at specific sites suggests that the patterns of breeding system variation are not linked to environmental factors, but are instead a consequence of the interplay between historical factors, such as dispersion patterns from glacial refugia and the sites of origin of mutations promoting the transition to asexuality.
\end{abstract}

Keywords: allozymes, breeding systems, Daphnia, parthenogenesis, zooplankton.

\section{Introduction}

The phylogenetic and ecological distribution of asexual organisms have played key roles in guiding efforts to understand the evolutionary significance of sexual reproduction (Williams, 1975; Bell, 1982). Interpretation of these data, however, relies upon the presumption that asexuals are reproductively isolated from their sexual ancestors (Williams, 1975; Lewis, 1987), and hence that reversion from asexuality to sexual reproduction is impossible. If the latter assumption proves false, then the distributions of asexuals may reveal

Correspondence: Dr Paul Hebert, Department of Zoology, University of Guelph, Guelph, Ontario, N1G 2W1, Canada. more about factors impacting the dynamic equilibrium between the adoption of asexuality and reversion to sexuality than about the factors responsible for the maintenance of sex.

There are few taxonomically isolated asexuals; most have close relatives which reproduce sexually. Indeed many asexuals, including all asexual fish and amphibians (Uzzell, 1970; Moore, 1984), rely on sperm donations from closely related species for either the initiation of egg cleavage (gynogens) or for co-incorporation with asexually transmitted segments of the genome (hybridogens). In a few of these cases, there is evidence that the donor sperm is incorporated into the genome and can be transmitted to the offspring (Bogart et al., 1989; Dawley, 1989). The bulk of asexuals have, 
however, escaped this reliance upon a sexual relative and produce eggs which develop without fertilization. It is becoming clear that in many of these taxa, the obligate associations inherent in gynogenesis or hybridogenesis (Vrijenhoek, 1984) are merely supplanted by facultative interactions (Lynch, 1984). There is growing evidence that purely asexual taxa are uncommon; broad-scale surveys often reveal relict sexual populations. Admittedly the evidence supporting such a breeding system variation is in most cases circumstantial, being reliant upon the detection of a shift from exclusively female populations at most sites to mixed gender populations at other localities (Tsurusaki, 1986). Moreover, some apparent examples of breeding system variation arise from flawed taxonomy, as deeper analysis reveals marked divergence between sexual and asexual forms. For example, Artemia salina was long thought to be a single species with varied reproductive behaviour but it is now clear that it is a species complex (Browne \& MacDonald, 1982). However, in other cases, there is compelling evidence for both breeding system variation and interactions between asexual and sexual segments of the taxon. The stick insect Bacillus rossius includes both sexual and asexual populations and matings between males and asexual females result in offspring which themselves reproduce sexually (Scali, 1982). In many other taxa with similar breeding system variation, sexual populations are diploid while asexuals are polyploid (Hughes, 1989). The rarity of diploid asexuals may reflect the importance of ploidy level shifts in producing reproductive isolation and hence protection against reversion to sexuality. However, there remains a number of species, such as Solenobia triquetrella (Seiler, 1961; Lokki et al., 1975) and Daphnia pulex (Beaton \& Hebert, 1988), in which both diploid asexuals and sexuals are known. However, none of these systems has been studied in sufficient detail to provide insight into the nature of interactions between the sexual and asexual populations.

The present study examines breeding system variation in the cladoceran crustacean Daphnia pulex and its most closely related congener $D$. pulicaria, which jointly dominate the zooplankton fauna in ponds across much of North America. Both species show breeding system variation with some populations reproducing by cyclic and others by obligate parthenogenesis. Cyclic parthenogenesis is the ancestral breeding system and the transition to obligate asexuality in $D$. pulex has been firmly linked to sex-limited meiosis suppression. Breeding studies have established that obligately asexual clones of this species are heterozygous for a sex-limited meiosis suppressor (Innes \& Hebert, 1988). Females of such clones produce only diploid eggs, but their male progeny undergo meiosis to produce haploid sperm which transmit the meiosis suppressor and elicit the adoption of asexuality by half of the offspring, which arise from matings with cyclically parthenogenetic females. The suppressor mutation spreads contagiously through 'infected' populations, rapidly freezing the genotypic diversity in its sexual ancestor (Hebert, 1983). The genetic characteristics of asexual populations of $D$. pulex conform with those expected if a meiosis suppressor was responsible for the adoption of asexuality. Clonal diversity is exceptionally high (Hebert et al., 1988, 1989a) and joint allozyme/mtDNA analysis has confirmed the polyphyletic origins of asexuality (Crease $e t$ al., 1989). Prior surveys of breeding systems, however, have revealed two anomalies - the sustained presence of sexual populations in regions dominated by asexuals (Hebert et al., 1989a) and an apparent regional variation in the dominant breeding system (Innes et al., 1986).

This paper aims to clarify the nature and extent of regional shifts in breeding system in both $D$. pulex and D. pulicaria at sites across Canada. Recent work established the presence of $F_{1}$ hybrids between these species and has shown that such hybrids always reproduce by obligate parthenogenesis (Hebert et al., 1989a; Crease \& Lynch, 1991). Earlier studies incorrectly classified these hybrids as asexual clones of $D$. pulex (Hebert \& Crease, 1983; Lynch 1983; Innes et al., 1986). It remains clear, however, that $D$. pulex s.s. shows variable reproductive behaviour, with some populations reproducing by cyclic and others by obligate parthenogenesis. Polyploid clones are common in the arctic but are apparently absent from more southerly sites (Beaton \& Hebert, 1988). It is also evident that breeding systems vary regionally; most Ontario populations reproduce by obligate parthenogenesis (Hebert et al., 1989a), whereas those from Illinois are cyclic parthenogens (Lynch, 1983). There is much less information available on $D$. pulicaria, but the results available suggest that this species also shows breeding system variation (Wagner, 1985). Because direct breeding system determinations are extremely time consuming, this study relies upon the inference of breeding systems from the genotypic characteristics of each population. Prior work has established the validity of this approach (Hebert et al., 1989a), which is contingent upon the observation that asexual populations contain few genotypes and show marked Hardy-Weinberg (HW) disturbances, while populations reproducing by cyclic parthenogenesis contain many genotypes and generally show concordance to HW expectations. 


\section{Materials and methods}

Collections of Daphnia were made in April to June of 1986-1991 from 30 or more ponds in each Canadian province. In the four eastern provinces (Nova Scotia, New Brunswick, Newfoundland, Prince Edward Island) collections were dominated by members of the Daphnia catawba complex (Brooks, 1957). D. pulex was absent from Newfoundland and rare in the other three eastern provinces so that collections at sites 28-32 originated from a small number of isolated ponds. In the remaining provinces, $D$. pulex $/ D$. pulicar$i a$ were common and collections were made from 8 to 12 ponds at each of 27 sites (Fig. 1). The ponds at these sites usually fell within a $25-\mathrm{km}$ radius, although, to ensure that populations were discrete, ponds sampled were at least $1 \mathrm{~km}$ apart. Site locations were chosen to ensure their uniform distributions across the portions of each province accessible by road and were, on average, $230 \mathrm{~km}$ distant from their nearest neighbour. Site locations are described by the name of the community which was central to the collection area (Table 1).

Most populations in eastern Canada were collected from shallow intermittent woodland pools, while many of the habitats in western Canada were sloughs. The latter habitats often have large surface areas and a maximum depth of 2 or more metres. Although not frozen to the bottom during the winter, they usually become anoxic and so lack fish. Daphnia populations in both habitat types are likely to be re-established each year from diapausing eggs. As populations were sampled shortly after egg hatch, genotypic frequencies were expected to approximate Hardy-Weinberg equilibrium in those populations reproducing by cyclic parthenogenesis.

Samples from each population containing members of the D. pulex/D. pulicaria complex were sorted in the field, frozen in liquid nitrogen and subsequently subjected to both morphological and allozyme analysis. Prior studies have not identified morphological characters which permit the unambiguous discrimation of $F_{1}$ hybrids from their parent taxa, but allozyme analysis (Hebert et al., 1989a) has revealed diagnostic substitions at two loci (Ldh, Pep). In this study Ldh phenotypes were employed in taxon recognition: individuals homozygous for the Ldh-F allele were classified as $D$. pulicaria, those homozygous for the $\mathrm{S}$ allele as $D$. pulex, and SF heterozygotes as $\mathrm{F}_{1}$ hybrids. A posteriori morphological studies on each population confirmed that individuals assigned to $D$. pulex and $D$. pulicaria showed the divergence in head shape characteristic of these species (Brooks, 1957; Brandlova et al., 1972). To assess the genotypic structure of each population, 44 individuals were scored for allozyme variation at six additional loci (Ao, Fum, Got, Mpi, Pgi, Pgm), which

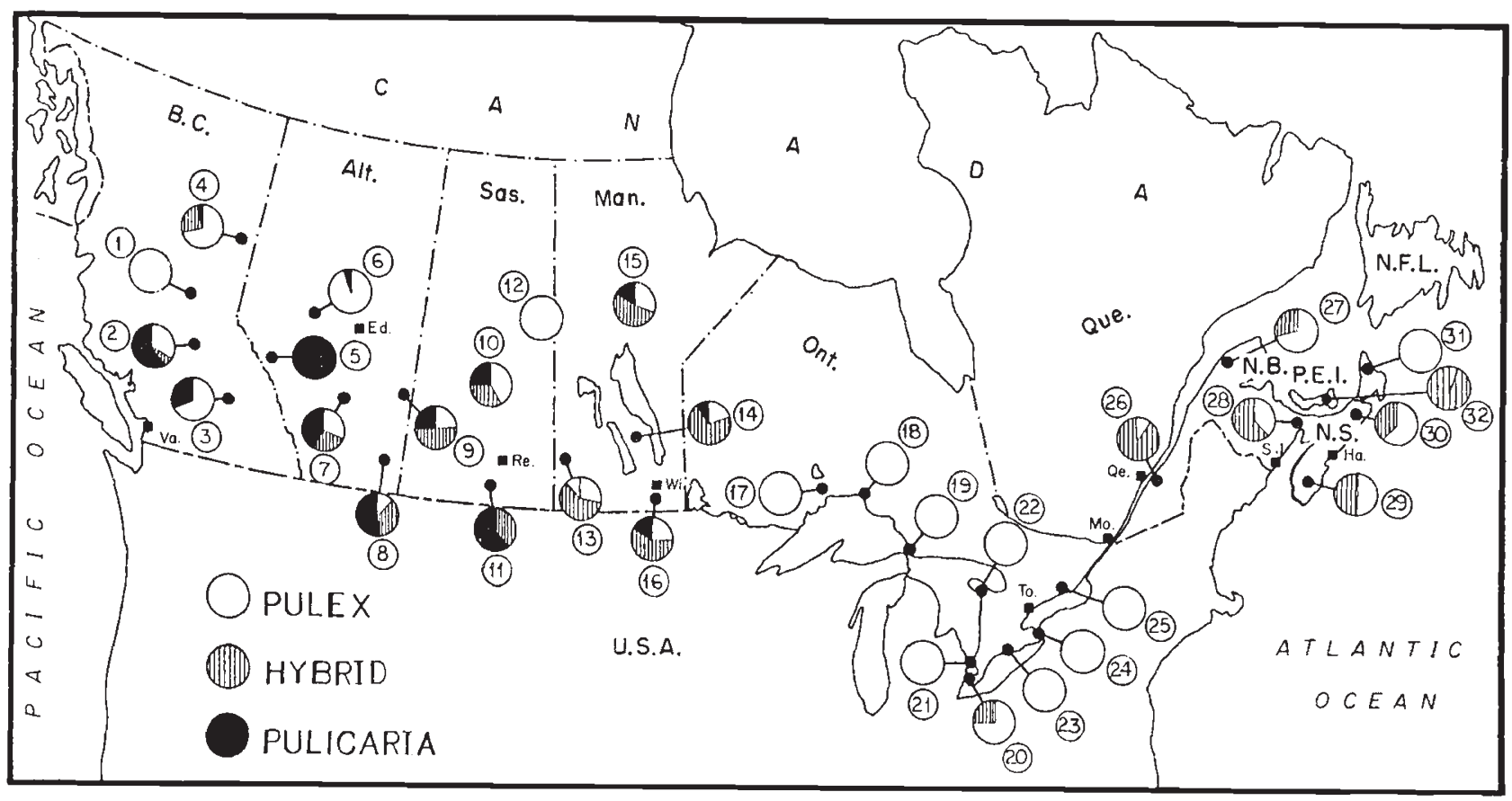

Fig. 1 Locations of the 32 sampling sites. Pie diagrams indicate the proportions of D. pulex, D. pulicaria and their $\mathrm{F}_{1}$ hybrids at each site. 
Table 1 Locations of the 32 sites at which populations of D. pulex/pulicaria were collected

\begin{tabular}{ll}
\hline Province & Locations and site designations \\
\hline British Columbia & $\begin{array}{l}\text { Prince George (1), Riske Creek (2), Kamloops (3), } \\
\text { Dawson Creek (4) } \\
\text { Jasper (5), Blue Ridge (6), Red Deer (7), } \\
\text { Alberta }\end{array}$ \\
Medicine Hat (8), Provost (9) & Prince Albert (10), Moose Jaw (11), Jan Lake (12) \\
Saskatchewan & Russell (13), Moosehorn (14), Thompson (15), \\
Manitoba & Dominion City (16) \\
& Red Rock (17), Marathon (18), Sault Ste. Marie (19), \\
Ontario & Windsor (20), Sarnia (21), Port Elgin (22), \\
& Long Point (23), Fort Erie (24), Peterborough (25) \\
Quebec & Ste Marie de Beauce (26), Rimouski (27) \\
New Brunswick & Moncton (28) \\
Nova Scotia & Yarmouth (29), Sherbrooke (30), Igonish Beach (31) \\
Prince Edward Island & Cavendish (32) \\
\hline
\end{tabular}

are commonly polymorphic. All electrophoresis was carried out on Titan III ${ }^{\circledast}$ cellulose acetate plates following standard methods (Hebert \& Beaton, 1989).

The genotypic characteristics of each population were summarized using three parameters: the number of multi-locus genotypes identified, the log-transformed probability of the observed genotypic distribution at polymorphic loci being in Hardy-Weinberg equilibrium, and the genotypic diversity ratio (GDR the observed number of multilocus genotypes divided by the expected number in a sample of the same size and with the same gene frequencies from a sexual population). Individual loci were treated as monomorphic when the frequency of the most common allele was greater than 0.9 . Populations monomorphic at all loci were excluded from further analysis because monomorphic loci provide no useful indication of breeding system. For the remaining populations, the three parameters were calculated following the methods described in Hebert et al. (1988). Decisions concerning the breeding system employed by individual populations were based on the following rules. Populations were classified as obligately asexual when the log probability was less than -2.00 (i.e. when the average probability of the genotypic array at each polymorphic locus being in Hardy-Weinberg equilibrium was $<0.01)$. Ordinarily such populations also had a low GDR $(<0.50)$. Populations were classified as consisting of cyclic parthenogens when the log probability was greater than -2.00 and the GDR was $>0.75$. Finally the breeding system of a population was classified as uncertain when the log probability of the geno- typic array was greater than -2.00 , but the GDR was $<0.75$.

Data collected in the present study were supplemented with the results of prior work at nine sites in Ontario (Hebert et al., 1988), permitting the comparison of breeding system diversity across Canada. Most individual populations were comprised entirely of $F_{1}$ hybrids or one of the parent species. D. pulicaria was not collected from ponds in eastern North America, but was prevalent in the west. Hybrids occasionally cooccurred with $D$. pulex in eastern Canada and with one or both parents in the west. To remove difficulties in breeding system diagnosis arising from the admixture of obligately asexual hybrids and a cyclically parthenogenetic population of their parent taxon, the genotypic properties were characterized separately for hybrids and each parent species represented by 20 or more individuals. Samples of less than 20 individuals per taxon were excluded from further analysis.

Unbiased genetic distances (Nei, 1978) were calculated among populations and the relatedness of populations assessed using the unweighted pair-group (UPGMA) clustering algorithm in BIOSYS-1 (Swofford \& Selander, 1989). Because of the very large number of populations, analysis of genetic distances was restricted to a comparison of mean gene frequency data for all populations from a specific province. As $D$. pulicaria was absent from ponds in eastern North America, supplemental gene frequency data for the species from lakes in northern Indiana were included for comparison. 
The extent of regional gene frequency divergence among populations of both $D$. pulex and $D$. pulicaria was determined using the methods of Wright (1978). A hierarchical approach was employed which examined the extent of gene frequency differentiation among populations at single sites $\left(F_{\mathrm{DS}}\right)$, among different sites in each province $\left(F_{\mathrm{SP}}\right)$ and among all provinces across Canada $\left(F_{\text {PT }}\right)$.

\section{Results}

\section{Taxon distributions}

Allozyme analyses were carried out on 11,346 individuals from 255 populations. This work (Table 2) established that $D$. pulex was broadly distributed across Canada, while $D$. pulicaria was restricted to ponds in the four western provinces. However, at these sites, $D$. pulicaria was common, comprising 30 per cent of the individuals. $F_{1}$ hybrids were also ubiquitous, although they were much less common in Ontario (4 per cent) than in the other provinces (30-46 per cent). In eastern Canada and Quebec, both hybrids and $D$. pulex were common but rarely co-occurred (Table 3 ), as more than 85 per cent of the ponds contained only one taxon. Opportunities for co-occurrence of taxa in Ontario were limited as $D$. pulex comprised 96 per cent of the collections. In the four western provinces the majority of ponds (48-83 per cent) contained only hybrids or one of their parent taxa. Hybrids cooccurred with one parent species in 12-39 per cent of ponds and with both parents in 5-14 per cent of ponds.

\section{Gene frequencies}

The allozyme surveys confirm that loci previously found to be polymorphic in Ontario/Illinois were also variable at sites across Canada. Few new alleles were detected in the analysis and, with the exception of the absence of allele 1 at Got and $A o$ in D. pulicaria, the two parent species shared identical allelic arrays (Table 4). Clear gene frequency differences were evident, however, between $D$. pulex and $D$. pulicaria in their zone of sympatry in western Canada (Table 5). All 19 alleles present at the six polymorphic loci showed significant differences $(P<0.05)$ in frequency between the two species, and in 15 of these cases hybrids possessed allele frequencies intermediate to those of their parent taxa. At single sites this pattern was often striking. For example, at the Riske Creek site

Table 2 Proportions of D. pulex, D. pulicaria and their $F_{1}$ hybrids in ponds across Canada

\begin{tabular}{lllll}
\hline & \multicolumn{1}{l}{ Taxon } & & & \\
\cline { 2 - 5 } Region & Individuals & Pulex & Hybrids & Pulicaria \\
\hline $\begin{array}{l}\text { Quebec and eastern } \\
\text { provinces }\end{array}$ & 1462 & 0.536 & 0.464 & 0.000 \\
$\begin{array}{l}\text { Ontario } \\
\text { Western provinces }\end{array}$ & 3895 & 0.960 & 0.040 & 0.000 \\
& 5989 & 0.403 & 0.296 & 0.301 \\
\hline
\end{tabular}

Table 3 Proportions of $D$. pulex group populations from each of seven regions across Canada consisting either of one taxon or of a mixture of taxa. $\mathrm{px}=$ pulex, $\mathrm{pc}=$ pulicaria, $\mathrm{F}_{1}=$ hybrid

\begin{tabular}{lccccccc}
\hline & & & & & & & Other \\
& $n$ & $\mathrm{px}$ & $\mathrm{F}_{1}$ & $\mathrm{pc}$ & $\mathrm{F}_{1}+\mathrm{px}$ & $\mathrm{F}_{1}+\mathrm{pc}$ & $\begin{array}{l}\text { mixtures } \\
\text { Eastern provinces }\end{array}$ \\
\hline Quebec & 21 & 0.48 & 0.38 & 0.00 & 0.14 & 0.00 & 0.00 \\
Ontario & 16 & 0.31 & 0.56 & 0.00 & 0.13 & 0.00 & 0.00 \\
Manitoba & 78 & 0.96 & 0.02 & 0.00 & 0.02 & 0.00 & 0.00 \\
Saskatchewan & 33 & 0.09 & 0.31 & 0.15 & 0.21 & 0.18 & 0.06 \\
Alberta & 21 & 0.20 & 0.14 & 0.14 & 0.14 & 0.24 & 0.14 \\
British Columbia & 43 & 0.37 & 0.09 & 0.12 & 0.05 & 0.25 & 0.12 \\
\hline
\end{tabular}




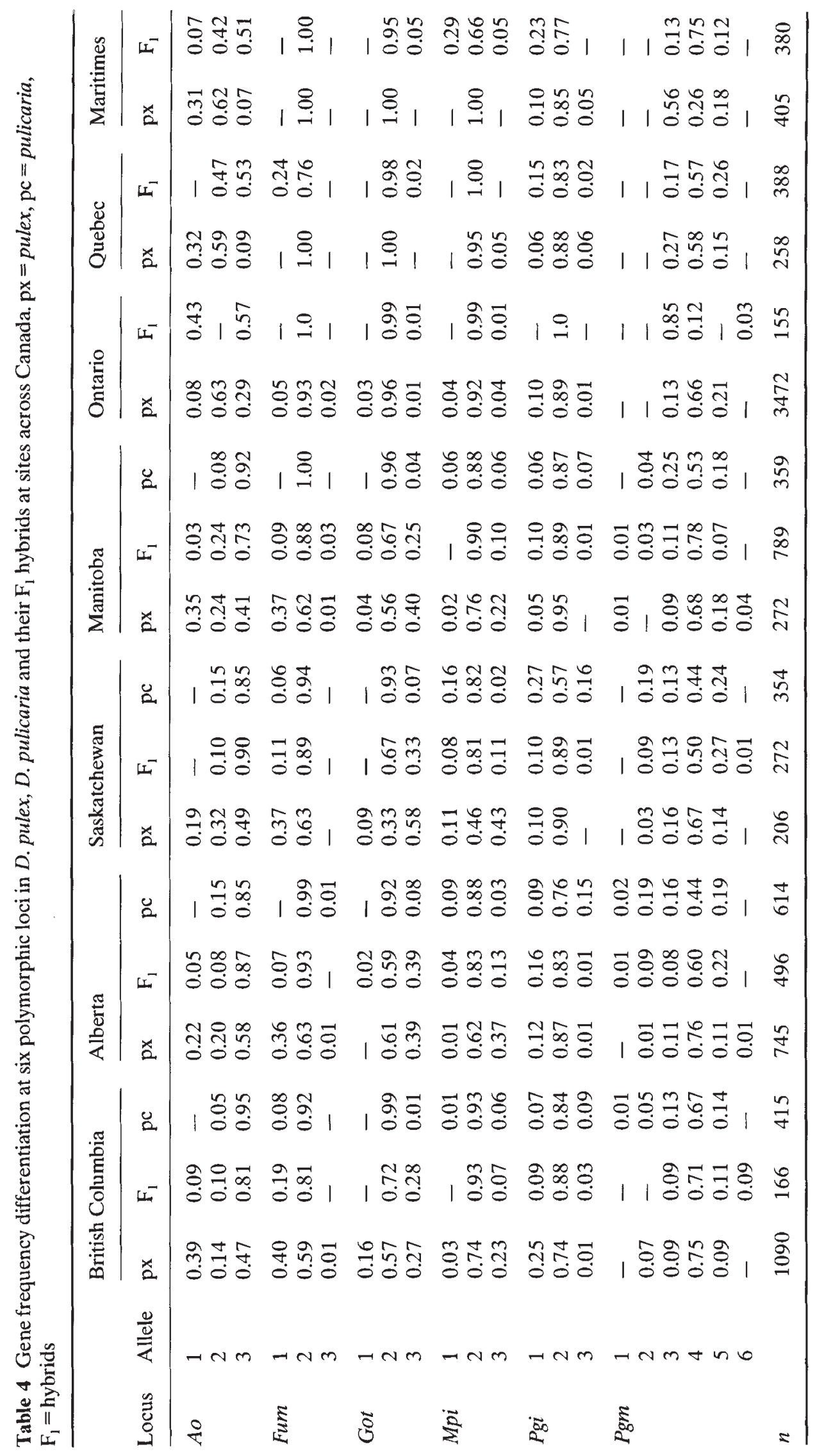




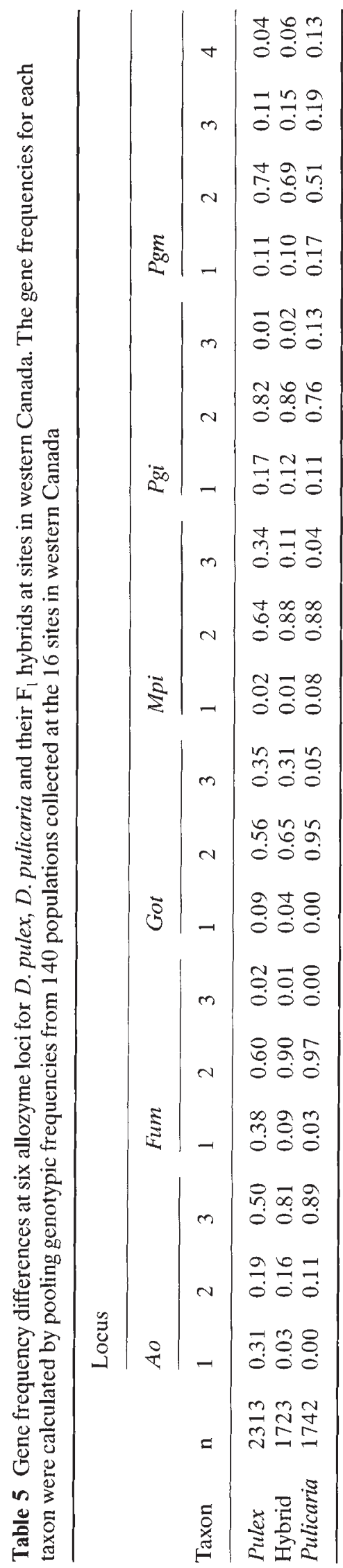

in British Columbia, D. pulicaria was homozygous for Got allele 2,D. pulex was homozygous for allele 3 and the hybrids were all Got 23 heterozygotes.

A hierarchical analysis of gene diversity (Table 6) indicated considerable gene frequency differentiation among local populations of $D$. pulicaria but little divergence among different sites in a single province or among the four western provinces. Populations of $D$. pulex showed a similar amount of gene frequency differentiation among local populations but in contrast to $D$. pulicaria there was also significant gene frequency divergence among different sites in a province. Further differentiation was not detected in a comparison of $D$. pulex populations from the four western provinces, although, when the analysis was extended to include sites across Canada, further differentiation was detected (Table 6). Examination of gene frequency data showed that the latter result arose as a consequence of marked gene freqency shifts (Fig. 2) at Mpi, Fum, and Got, coincident with the forest/prairie ecotone that occurs near the Manitoba/Ontario border (Fig. 2).

The genetic distance analysis (Fig. 3) confirmed that $D$. pulex was separable into eastern and western subgroups. The same analysis established that $D$. pulicaria from ponds in western Canada were very genetically similar, but divergent from the lake populations in Indiana. Despite their regional differentiation, $D$. pulex and $D$. pulicaria were clearly distinct from one another. There was, however, evidence of limited gene exchange between the two species. Pgm allele 2 was, for example, absent from $D$. pulex in eastern Canada, but present at low frequency in western Canadian populations where this allele was common in D. pulicaria. Conversely, the presence of the Fum allele 1 and Got allele 3 at low incidence in $D$. pulicaria may be linked to their abundance in western populations of $D$. pulex.

\section{Genotypic characters and breeding system assignments}

Populations showed considerable variation in the three parameters chosen to characterize genotypic diversity (Fig. 4). The number of clones in single populations varied from 1 to 42 , and the genotypic diversity ratio ranged from 0.10 to 1.15 . Genotypic frequencies in some populations approximated Hardy-Weinberg (HW) expectations while in others deviations were large.

Populations in Quebec and eastern Canada shared similar genotypic characteristics with most populations containing only 1 or 2 clones, and showing both pronounced HW deviations and a low GDR. In Ontario a few populations showed high clonal diversity, but most had low clonal diversity and low GDR. By contrast, 
Table 6 Hierarchical analysis of gene frequency diversity in populations of $D$. pulex and $D$. pulicaria for sites in the four western provinces and for sites across Canada

\begin{tabular}{|c|c|c|c|c|c|c|c|c|c|c|c|c|}
\hline & \multicolumn{8}{|c|}{ Western provinces } & \multirow{2}{*}{\multicolumn{4}{|c|}{$\frac{\text { Canada }}{\text { Pulex }}$}} \\
\hline & \multicolumn{4}{|c|}{ Pulicaria } & \multicolumn{4}{|l|}{ Pulex } & & & & \\
\hline & $D S$ & $S P$ & $P T$ & $D T$ & $D S$ & $S P$ & $P T$ & $D T$ & $D S$ & $S P$ & $P T$ & $D T$ \\
\hline Ao & 0.47 & -0.07 & -0.01 & 0.43 & 0.35 & 0.13 & 0.02 & 0.43 & 0.36 & 0.09 & 0.13 & 0.49 \\
\hline Fum & 0.37 & 0.01 & 0.00 & 0.37 & 0.21 & 0.10 & -0.03 & 0.27 & 0.22 & 0.09 & 0.14 & 0.39 \\
\hline Got & 0.12 & 0.07 & -0.01 & 0.18 & 0.38 & 0.31 & -0.05 & 0.55 & 0.40 & 0.28 & 0.18 & 0.64 \\
\hline Mpi & 0.61 & -0.06 & 0.01 & 0.59 & 0.38 & 0.05 & -0.03 & 0.40 & 0.38 & 0.04 & 0.12 & 0.47 \\
\hline Pgi & 0.26 & 0.02 & 0.03 & 0.29 & 0.13 & 0.08 & 0.04 & 0.23 & 0.26 & 0.04 & 0.02 & 0.30 \\
\hline Pgm & 0.22 & 0.01 & 0.01 & 0.23 & 0.19 & -0.02 & 0.00 & 0.22 & 0.28 & 0.06 & 0.04 & 0.35 \\
\hline Mean & 0.33 & 0.00 & 0.01 & 0.33 & 0.29 & 0.13 & -0.02 & 0.37 & 0.32 & 0.10 & 0.11 & 0.45 \\
\hline
\end{tabular}

$D S=$ differentiation among populations $(D)$ at single sites $(S) ; S P=$ differentiation among different sites $(S)$ in a province;

$P T=$ differentiation among the different provinces $(P)$ in the total area considered $(T) ; D T=$ differentiation among populations

$(D)$ from the total area studied $(T)$.

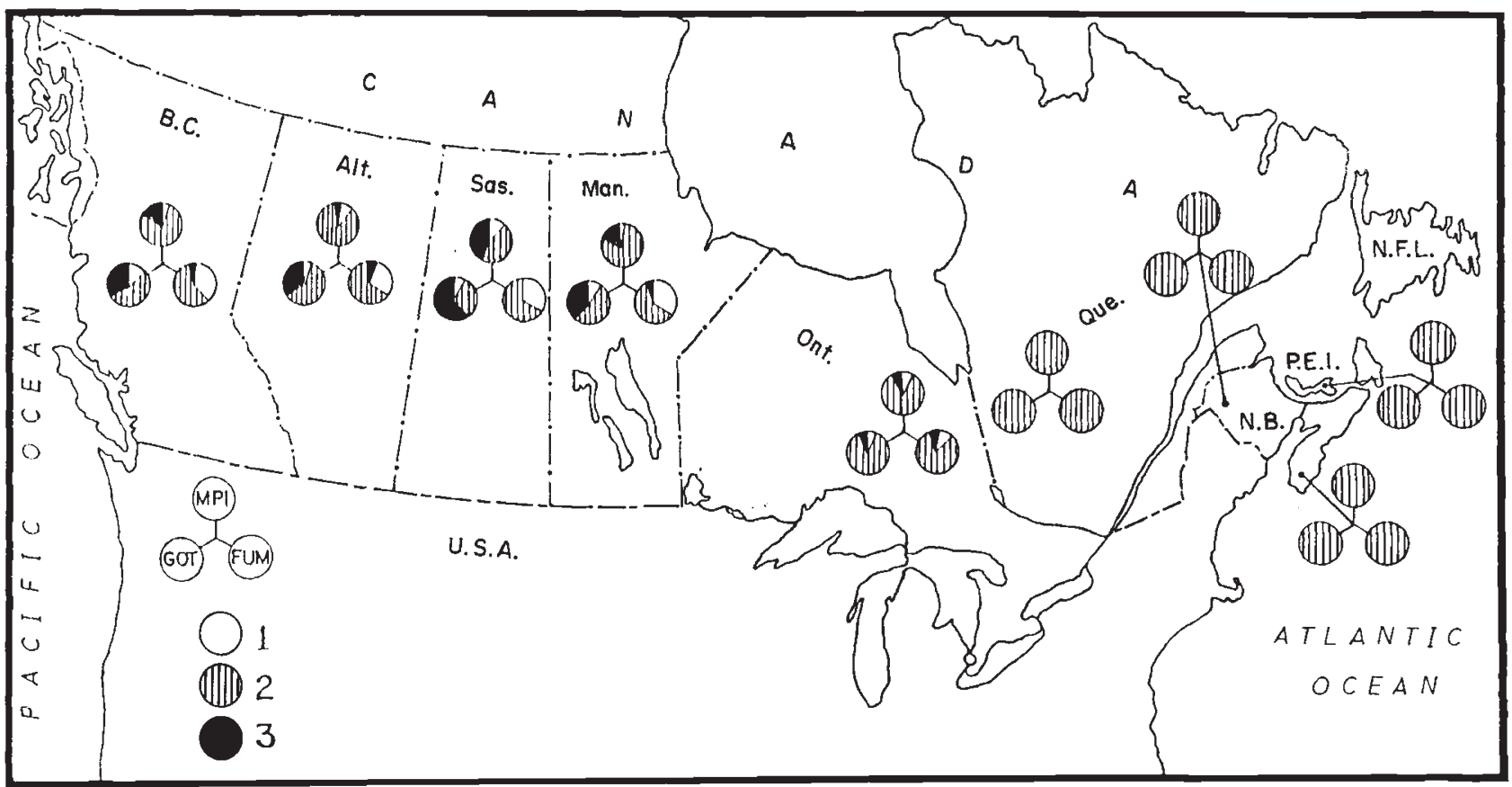

Fig. 2 Gene frequency divergence at Got, Fum and $M p i$ for Canadian populations of $D$. pulex. The gene frequencies are the mean for all populations from each province.

with few exceptions, clonal diversities in western ponds were higher, ranging from 5 to 42 . Ponds containing fewer than 10 clones typically had a low GDR and large HW deviations, while higher diversity ponds showed agreement with HW expectations and a GDR close to 1.0 .

The breeding system assignments made it clear that most populations of $D$. pulicaria in Manitoba, Saskatchewan, and Alberta reproduce by obligate asexuality (Fig. 5). However, cyclically parthenogenetic populations were found to be common in British Columbia, and at one site (6) in northern Alberta. The pattern of breeding system variation in $D$. pulex was more complex. Populations in eastern Canada and Quebec were invariably obligately asexual (Fig. 6), as were the bulk of Ontario populations. However, sexual populations occurred at a few sites in southern Ontario, and dominated, with few exceptions, sites in western Canada. Populations dominated by putative hybrids ordinarily showed low clonal diversity making 


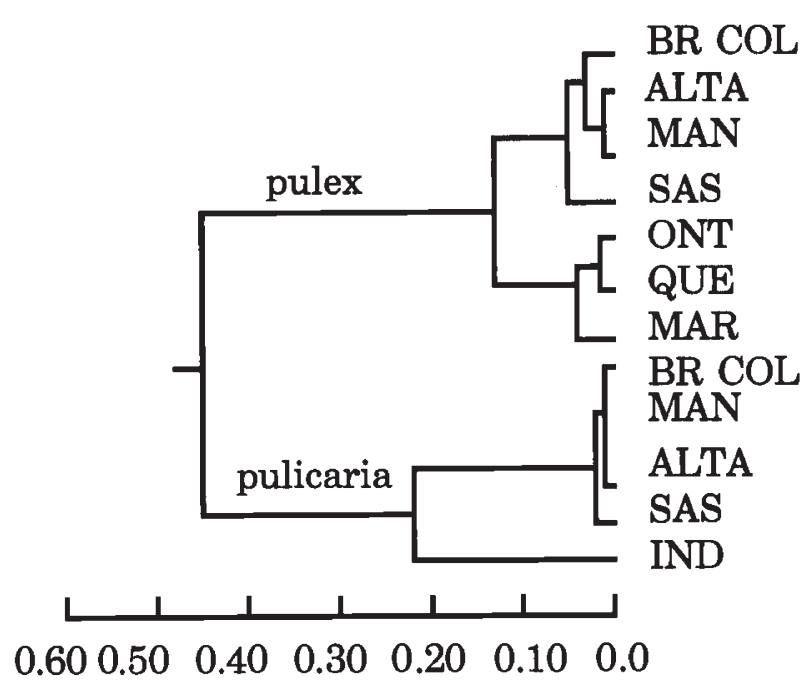

Fig. 3 UPGMA clustering of Nei's genetic distance among populations of $D$. pulex and $D$. pulicaria based upon gene frequencies at seven polymorphic allozyme loci. Gene frequencies were pooled for all populations of a specific taxon from each province, with the exception of eastern Canada where gene frequencies for populations from the three Maritime provinces were pooled. The data on $D$. pulicaria were augmented by the inclusion of gene frequency data on populations from lakes in northern Indiana.

it clear that they were obligately asexual. However, some populations in western Canada contained a substantial number of clones and need to be more fully examined to exclude the possibility that they represent rare LDH polymorphisms in $D$. pulex or $D$. pulicaria. Ephippial eggs were hatched from 10 hybrid isolates from western Canada and the resultant offspring showed no segregation at loci heterozygous in their parent, confirming that each clone reproduced asexually.

\section{Clonal diversity in asexual populations}

Populations of $D$. pulex, D. pulicaria and $\mathrm{F}_{1}$ hybrids reproducing by obligate parthenogenesis were identified at sites across Canada. When the results for all three groups are considered, there is a clear pattern in clonal richness with populations in western Canada showing the highest diversity (Fig. 7). Restricting the analysis solely to populations containing only hybrids produced the same pattern; western populations contained 3-4 times as many clones at those in the east (Table 7).

\section{Discussion}

Most genetic work on asexual organisms has involved the analysis of genotypic diversity in populations from one or a few sites. Yet the limited number of more comprehensive surveys has established that reproductive systems are not invariant. Patterns of clonal diversity often vary regionally, and in some cases relict populations of sexual ancestors have been identified. The generality of these conclusions is supported by more anecdotal information such as the local occurrence of males, which may signal sexual reproduction, in populations of many asexual taxa. The limited results so far available provide much support for the importance of interactions between sexuals and asexuals, and especially the potential role of sexual populations in sustaining clonal diversity in their asexual derivatives.

The present study represents the first attempt to assess breeding system diversity on a continental scale in a cladoceran crustacean employing two divergent breeding systems. The study provides a comprehensive analysis of breeding system variation in Canadian populations of $D$. pulex, but information on $D$. pulicaria was limited by its absence from ponds in eastern North America. The allozyme surveys established that these two species share, with few exceptions $(L p h, P e p)$, the same polymorphic loci and the same allelic arrays at these loci. The clear divergence in allele frequencies at polymorphic loci confirms that introgression between the species was rare or absent at sites of sympatry. The high levels of genetic diversity in North American populations of these species contrasts with the paucity of variation in European populations of D. pulex and D. pulicaria (Hebert et al., 1989b; R. D. Ward and M. A. Bickerton, personal observation). The difference suggests a recent colonization of Eurasia or severe population bottlenecks, perhaps during the Pleistocene.

The allozyme analyses revealed that ponds in eastern Canada contained only D. pulex or $\mathrm{F}_{1}$ hybrids, a result congruent with prior work on ponds in Ontario and the mid-western United States. D. pulicaria is known to be common in this region but is restricted to lakes. By contrast, in western Canada $D$. pulex, $D$. pulicaria, and their $F_{1}$ hybrids were all found to occur in ponds. This result was not unexpected, as prior taxonomic studies established the presence of $D$. pulicaria in western ponds (Brooks, 1957; Brandlova et al., 1972).

The present study has made it clear that $F_{1}$ hybrids between $D$. pulex and $D$. pulicaria are common at sites across Canada and reproduce asexually. Their prevalance in western Canada was not unexpected in light of their predominance in grassland pools in the Great Lakes region (Hebert \& Crease, 1983). Whereas the initial conclusion concerning the hybrid origin of these clones was based on the results of allozyme surveys 

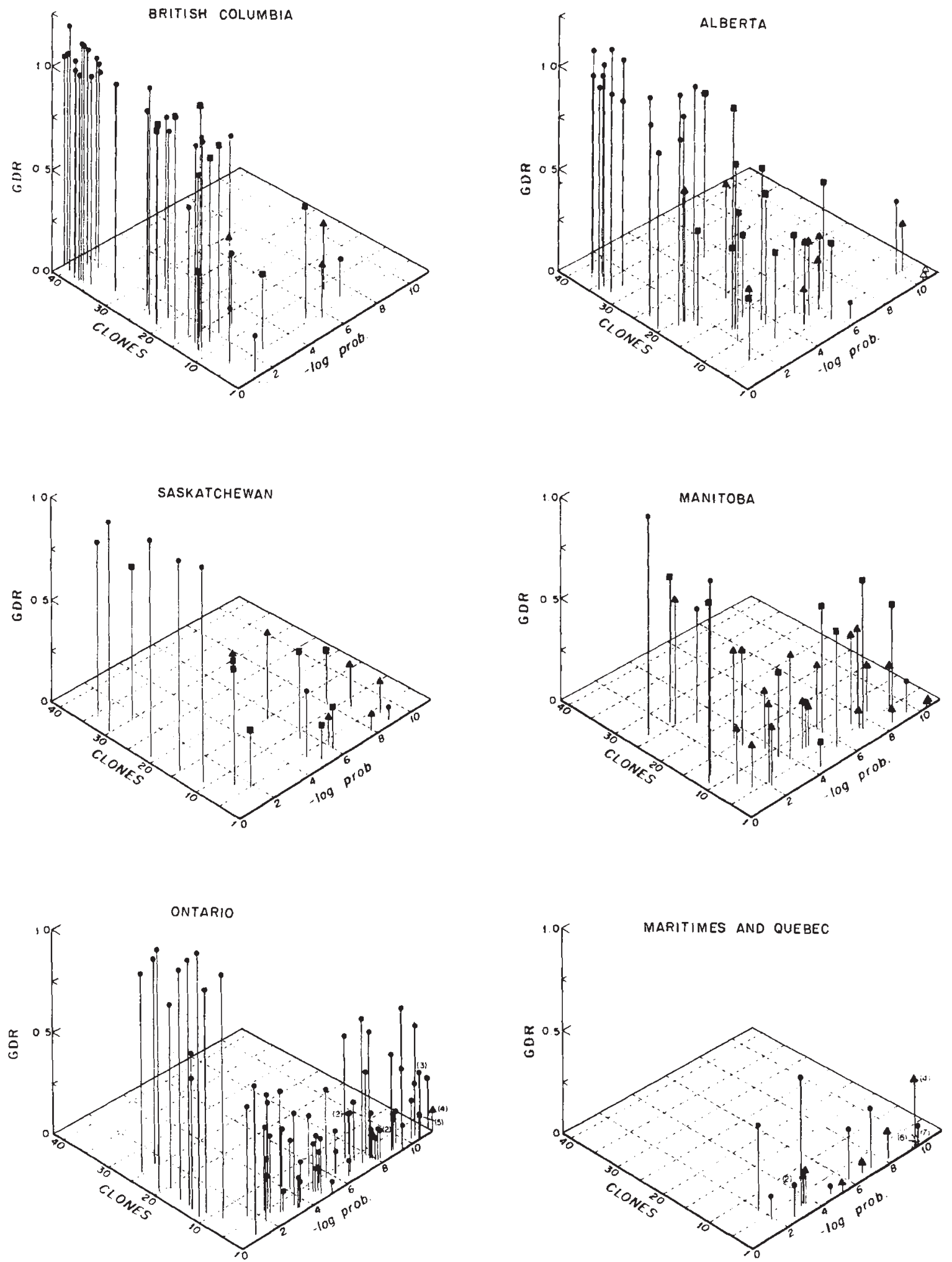

Fig. 4 Genotypic characteristics of D. pulex group populations at sites across Canada. $(\bullet)$ pulex, $(\bullet)$ pulicaria, $(\Delta) \mathrm{F}_{1}$ hybrid. 


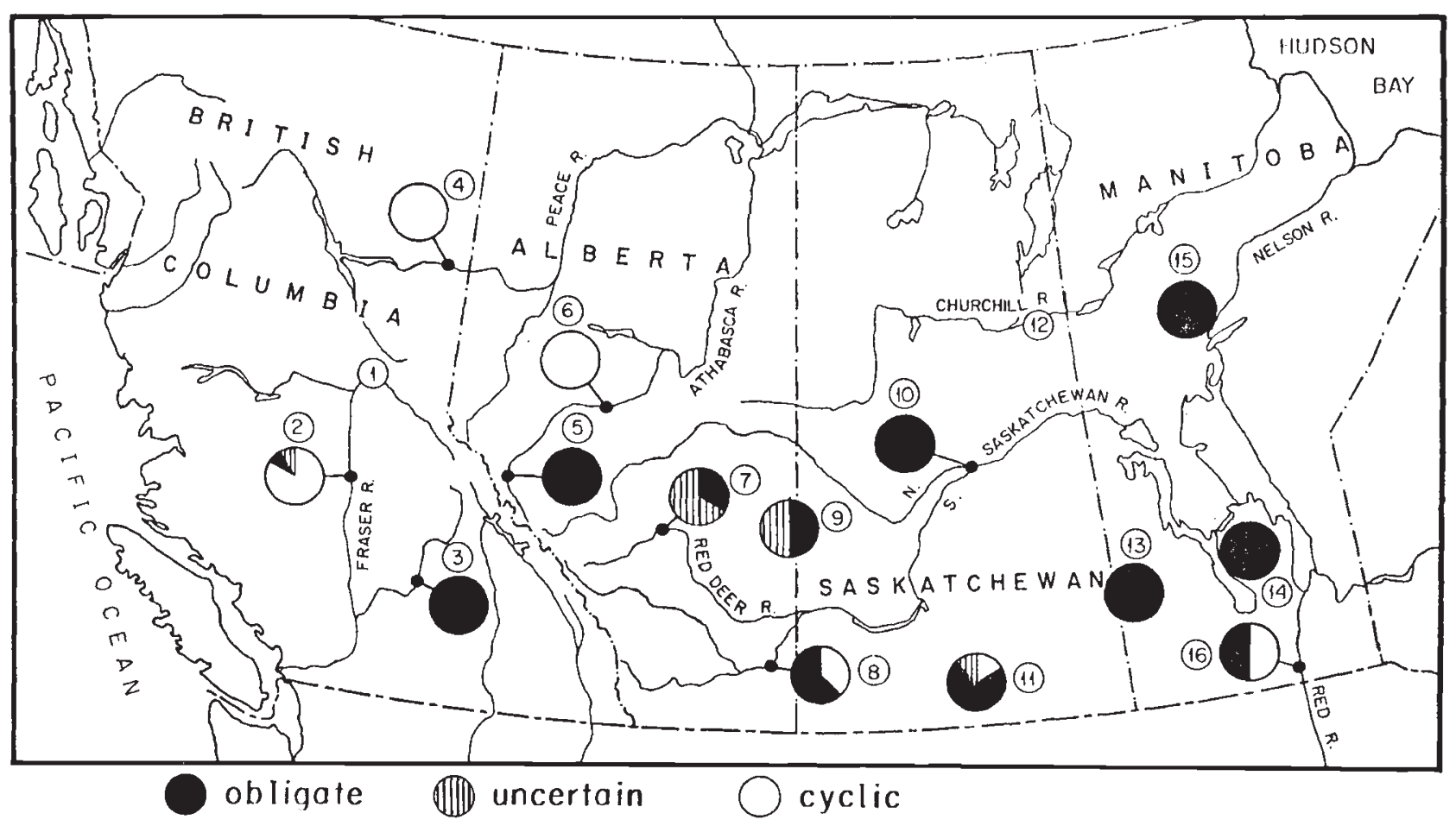

Fig. 5 Breeding system designations for populations of D. pullicaria in four western provinces.

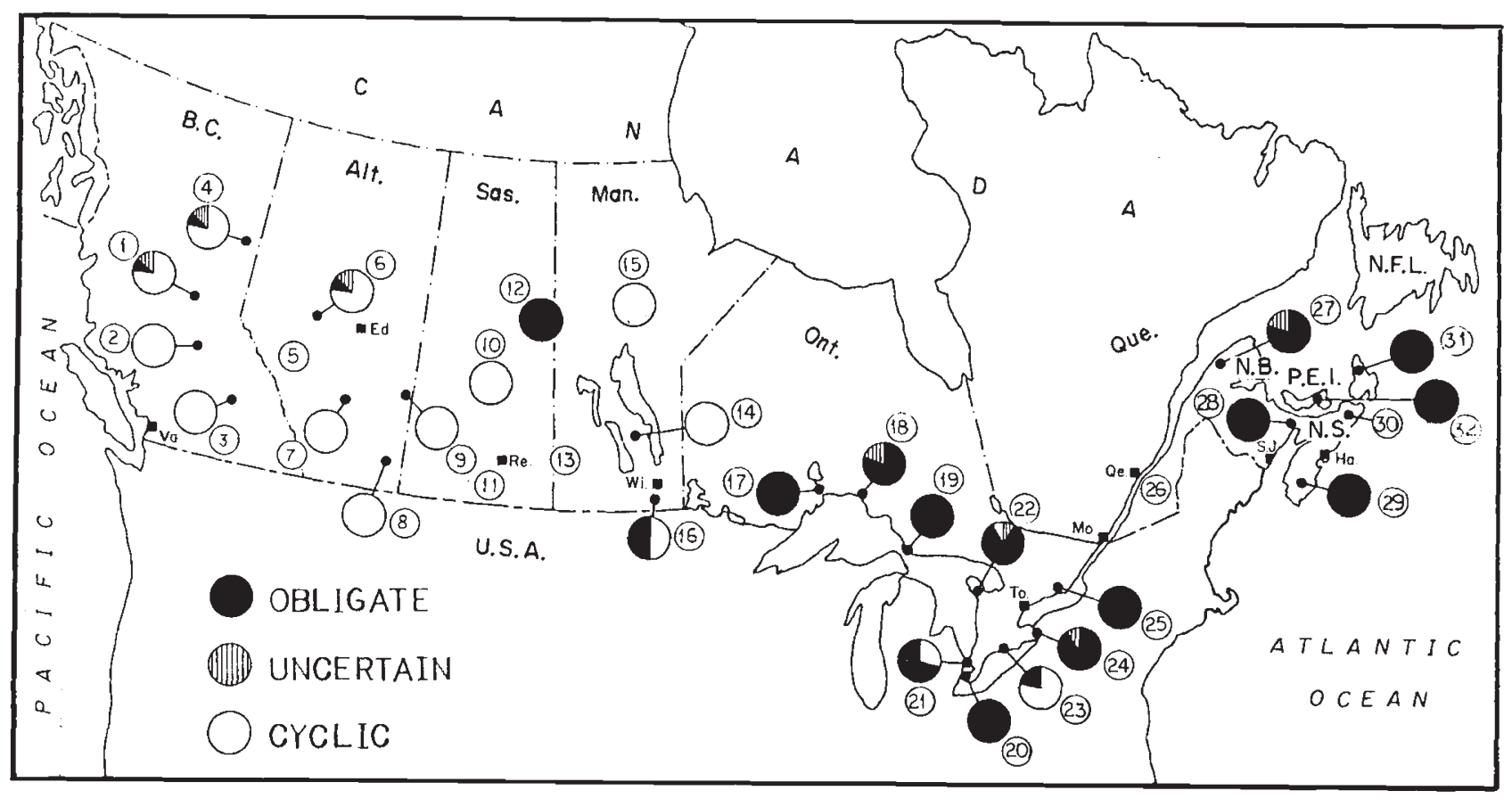

Fig. 6 Breeding system designations for populations of D. pulex at sites across Canada.

(Hebert et al., 1989a), this conclusion has recently been supported by rDNA analysis (Crease \& Lynch, 1991). The present study revealed the intermediacy of allele frequency in the hybrids relative to their putative parent taxa at sites in western Canada, providing additional evidence of their hybrid origin. Opportunities for the synthesis of new hybrid clones are undoubtedly most frequent in western Canada, where the parent 


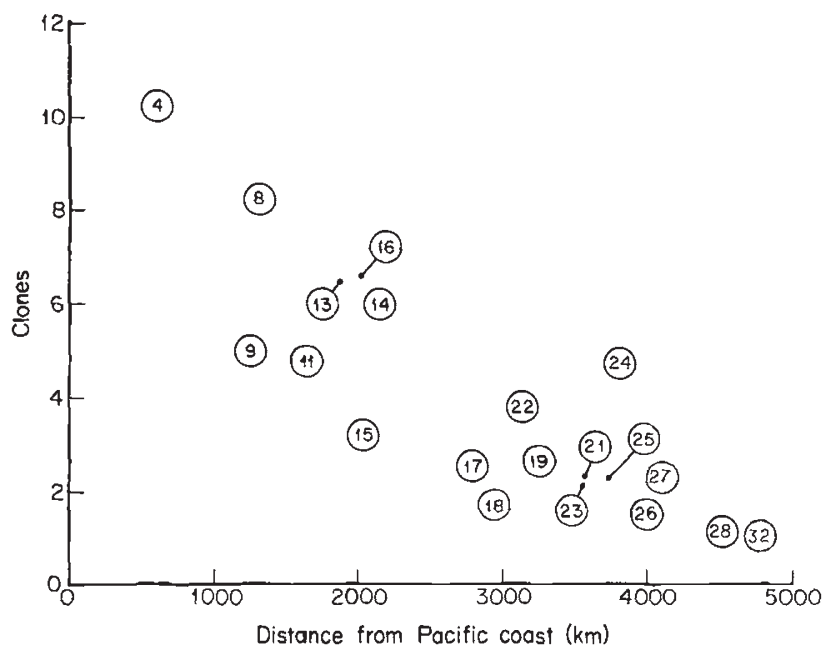

Fig. 7 Shifts in the clonal diversity of asexual populations of D. pulex/D. pulicaria at 20 sites across Canada. Distances are shown between each site and a reference point (Prince Rupert) on the Pacific Coast.

Table 7 Variation in the average number of clones per pond for habitats containing only $F_{1}$ hybrids

\begin{tabular}{|c|c|c|c|}
\hline & \multirow[b]{2}{*}{ Number of populations } & \multicolumn{2}{|c|}{ Clones } \\
\hline & & $\bar{x}$ & s.d. \\
\hline Eastern Provinces & 8 & 1.00 & 0 \\
\hline Quebec & 9 & 1.44 & 0.73 \\
\hline Ontario & 2 & 2.00 & 1.41 \\
\hline Manitoba & 10 & 5.00 & 2.90 \\
\hline Saskatchewan & 3 & 7.00 & 7.00 \\
\hline Alberta & 4 & 3.25 & 2.63 \\
\hline British Columbia & 1 & 4.00 & - \\
\hline
\end{tabular}

taxa often co-occur. It might be anticipated that hybrids in eastern Canada would be derived from this area, but their genotypic characteristics (e.g. absence of Got allele 3 ) suggest they are synthesized locally, and there are rare reports of co-occurrence of the parent taxa (Hebert et al., 1989a). The much higher diversity of hybrid clones in western Canada suggests linkage between clonal richness and the rate of clonal synthesis.

While $F_{1}$ hybrids reproduced by obligate parthenogenesis, their parent taxa showed striking regional variation in breeding system. All populations of $D$. pulex in eastern Canada reproduced by obligate asexuality, as did the bulk of those in Ontario. By contrast, most populations of this species in western Canada were cyclic parthenogens, a result congruent with prior work showing the dominance of the same mode of reproduction in $D$. pulex populations from the mid-western United States (Lynch, 1983; Innes et al., 1986). Earlier reports of asexual populations from this area refer almost exclusively, if not entirely, to $F_{1}$ hybrids. The results suggest there is a narrow transition zone in $D$. pulex between sexually reproducing western populations and asexually reproducing eastern populations. The position of this zone coincides roughly with the boundaries of the prairie and eastern woodland biomes. Allozymes frequencies at the Ao, Got, Fum and $M p i$ loci showed a marked shift coincident with the transition. Crease et al. (1990) similarly showed that mtDNA phenotypes of asexual populations from deciduous forest habitats are distinct from those found in sexual priarie populations. Thus, existing data suggest that major shifts in allozyme/mtDNA phenotypes coincide with the breeding system transition. Any effort to account for the distributional pattern of asexuality in $D$. pulex is complicated, however, by the need to consider the reproductive behaviour of $D$. pulicaria. The present study revealed that, in contrast to lake populations in eastern North America, $D$. pulicaria from priarie ponds are obligately asexual. The dominance of obligate asexuals in these habitats accounts for an earlier report of the rarity of males in this region (Brooks, 1957). In contrast to the situation on the prairies, cyclic parthenogenesis was the dominant mode of reproduction in $D$. pulicaria from British Columbia and from one site in Alberta.

The shifts in dominant breeding systems of both $D$. pulex and $D$. pulicaria appear linked to major physiographic or habitat boundaries. Most populations of $D$. pulex from sites east of the forest/priarie ecotone are obligately asexual, while those in the west are cyclic parthenogens. By contrast, populations of $D$. pulicaria from the priaries are obligately asexual, while those in eastern Canada and those west of the Rockies are cyclic parthenogens. The divergence in breeding system distributions between the species suggests that there is no simple linkage between breeding system and habitat characteristics.

While the regional shifts in breeding system were clear, anomalies were detected. Some sites consisted, for example, of populations with an 'inappropriate' breeding system. For example, all populations of $D$. pulex from site 12 in western Canada consisted entirely of obligate asexuals instead of the usual cyclic parthenogens. Aside from this local shift in breeding system, there was also a high proportion of sites (29 per cent for $D$. pulicaria, 26 per cent for $D$. pulex) at which component populations showed variable breeding systems. Such co-occurence in unexpected as the meiosis suppression model predicts that, once introduced into an area, the mutation should rapidly bring about the conversion to asexuality (Hebert, 1983). It 
has been suggested that the persistence of cyclic parthenogens in regions dominated by asexuals may reflect their possession of a gene(s) conferring protection from conversion (Hebert et al., 1989a). However, further experimental studies are needed to examine the interaction between the cyclic and obligately asexual populations.

The macrogeographic pattern of breeding system variation in $D$. pulex is most readily explained by assuming that the current continuous distribution of this species across North America is a consequence of dispersal from two separate glacial refugia, and that obligate asexuality arose in the eastern refugium. This conclusion is supported by the coincidence of the breeding system shift with a discontinuity in allozyme and mtDNA frequencies. However, prior work has made clear that an east/west shift in breeding system does not occur in the Arctic as all populations in the tundra habitats are obligately asexual (Hebert \& Loaring, 1986; Weider \& Hebert, 1987; Weider et al., 1987; Wilson \& Hebert, 1992). Explaining the divergence between temperate and Arctic populations is complicated by the polyploid nature of most Arctic clones versus the diploid state of temperate zone clones (Beaton \& Hebert, 1988). The ubiquity of asexual clones in the Arctic does suggest either their broad distribution along the margin of the receding ice front or their displacement of diploid sexuals in the western Arctic. The presence of obligately asexual ecotypes adapted to cold environments provides a possible explanation for the dominance of asexual $D$. pulex at the northern site where they were detected in western Canada.

Efforts to explain breeding system variation in $D$. pulicaria confront a similar complexity. In eastern North America, the species appears invariably to reproduce by cyclic parthenogenesis (P. D. N. Hebert, personal observation) but on the priaries most populations reproduce by obligate parthenogenesis. Although D. pulicaria occupies lakes alone in eastern Canada, it is found in both pond and lake habitats in the west. Limited analysis has shown that populations of $D$. pulicaria from lakes in western North America often reproduce by obligate asexuality, suggesting that the breeding system shift is not dependent upon a habitat shift. This conclusion is further reinforced by the presence of cyclically parthenogenetic populations of $D$. pulicaria in ponds throughout British Columbia. The persistence of cyclic parthenogens in this area is most readily explained by assuming that the relative genetic isolation of these populations has protected them from conversion to asexuality.

In summary, patterns of breeding system diversity in the $D$. pulex group hint at a complex interplay of habitat characteristics, history and genetic parameters. There is no simple linkage of breeding system to habitat type but there is an indication that asexuality is favoured, probably because of its association with polyploidy, in cold environments. Historical factors appear important in accounting for the broad geographical patterning of breeding systems, whereas the local co-occurrence of sexuals and asexuals seems likely to be tied to genotypic diversity at loci controlling meiotic behaviour.

\section{Acknowledgements}

This research programme was supported by an NSERC Operating Grant to PDNH and an International Scientific Exchange Award to RDW from NSERC and the Royal Society. R. Allison provided much assistance in both field work and data analysis. Comments by M. Beaton, M. Boileau, J. Bogart and D. Innes aided in honing the manuscript.

\section{References}

BEATON, M. J. AND HEBERT, P. D. N. 1988. Geographical parthenogenesis and polyploidy in Daphnia pulex Leydig. Am. Nat., 132, 837-845.

BELL, G. 1982. The Masterpiece of Nature: the Evolution and Genetics of Sexuality. Croom Helm, London.

BRANDLOVA, J., BRANDL, Z. AND FERNANDO, C. H. 1972. The Cladocera of Ontario with remarks on some species and distribution. Can. J. Zool., 50, 1373-1403.

BOGART, J. P., ELINSON, E. P. AND LICHT, L. E. 1989. Temperature and sperm incorporation in polyploid salamanders. Science, 246, 1032-1034.

BROOKS, J. L. 1957. The systematics of North America Daphnia. Mem. Conn. Acad. Arts Sci., 13, 1-180.

BROWNE, R. A. AND MACDONALD, G. H. 1982. Biogeography of the brine shrimp Artemia: distribution of parthenogenetic and sexual populations. J. Biogeogr., 9, 331-338.

CREASE, T. J, AND LYNCH, M. 1991. Ribosomal DNA variation in Daphnia pulex reproducing by cyclic and obligate parthenogenesis. Mol. Biol. Evol., 8, 620-640.

CREASE, T. J., LYNCH, M. AND SPITZE, K. 1990. Hierarchical analysis of isozyme and mitochondrial DNA variation in Daphnia pulex. Mol. Biol. Evol., 7, 444-458.

CREASE, T. J., STANTON, D. J. AND HEBERT, P. D. N. 1989. Polyphyletic origins of asexuality in Daphnia pulex. II. Mitochondrial DNA variation. Evolution, 43, 1016-1026.

DAWLEY, R. M. 1989. An introduction to unisexual vertebrates. In; Dawley, R. M. and Bogart, J. P. (eds), Evolution and Ecology of Unisexual Vertebrates. New York State Museum, Albany.

HEBERT, P. D. N. 1983. Clonal diversity in cladoceran populations. In: King, C. E., and Dawson, P. S. (eds), Population Biology: Retrospect and Prospect. Columbia University Press, New York. pp. 37-59. 
HEBERT, P. D. N. AND BEATON, M. J. 1989. Methodologies for allozyme analysis using cellulose acetate electrophoresis. Helena Laboratories, Beaumont, Texas.

HEBERT, P. D. N., BEATON, M. J., SCHWARTZ, S. S. AND STANTON, D. J. 1989a. Polyphyletic origins of asexuality in Daphnia pulex. I. Breeding system variation and levels of clonal diversity. Evolution, 43, 1004-1015.

HEBERT, P. D. N., AND CREASE, T. J. 1983. Clonal diversity in populations of Daphnia pulex reproducing by obligate parthenogenesis. Heredity, 51, 353-369.

HEBERT, P. D. N. AND LOARING, J. M. 1986. Systematics of the Daphnia pulex complex: Morphological variation in an agamic complex and description of a species new to North America. Biochem. Syst. Ecol., 14, 333-340.

HEBERT, P. D. N., SCHWARTZ, S. S. AND HRBACEK, J. 1989b. Patterns of genotypic diversity in Czechoslovakian Daphnia. Heredity, 62, 207-216.

HEBERT, P. D. N., WARD, R. D. AND WEIDER, L. J. 1988. Clonaldiversity patterns and breeding-system variation in Daphnia pulex, an asexual-sexual complex. Evolution, 42, 147-159.

HUGHes, R. N. 1989. A Functional Ecology of Clonal Animals. Chapman and Hall, London.

INNES, D. J. AND HEBERT, P. D. N. 1988. The origin and genetic basis of obligate parthenogenesis in Daphnia pulex. Evolution, 42, 1024-1035.

INNES, D. J., SCHWARTZ, S. S. AND HEBERT, P. D. N. 1986. Genotypic diversity and variation in mode of reproduction among populations in the Daphnia pulex group. Heredity, 57, 345-355.

LEWIS, Jr. W. M. 1987. The cost of sex. In: Stearns, S. C. (ed.), The Evolution of Sex and its Consequences. BirkhauserVerlag, Basel.

LOKKI, J., SUOMALAINEN, E., SAURA, A. AND LANKINEN, P. 1975. Genetic polymorphism and evolution in parthenogenetic animals II. Diploid and polyploid Solenobia triquetrella (Lepidoptera: Psychidae). Genetics, 79, 513-525.

LYNCH, M. 1983. Ecological genetics of Daphnia pulex. Evolution, 37, 358-374.

LYNCH, M. 1984. Destabilizing hybridization, general-purpose genotypes and geographical parthenogenesis. Quart. Rev. Biol., 59, 257-290.

MOORE, w. S. 1984. Evolutionary ecology of unisexual fishes. In: Turner, B. J. (ed.), Evolutionary Genetics of Fishes. Plenum, New York. pp. 329-397.
NEI, M. 1978. Estimation of average heterozygosity and genetic distance from a small number of individuals. Genetics, 89, 583-590.

SCALI, v. 1982. Evolutionary biology and speciation of the stick insect Bacillus rossius (Insecta, Phasmatodea). In: Barigozzi, C. (ed.), Mechanisms of Speciation. A. R. Liss, New York.

SEILER, J. 1961. Untersuchungen über die Entstehung der Parthenogenese bei Solenobia triquetrella F. R. (Lepidoptera, Psychidae) III. Die geographische Verbreitung der drei Rassen von Solenobia triquetrella (bisexuell, diploid und tetraploid parthenogenetisch) in der Schweiz und in den angrenzenden Lädern und die Beziehung zur Eiszeit. Bemerkungen über die Entstehung der Parthenogenese. $Z$. Vererb., 92, 261-316.

SWOFFORD, D. L. AND SELANDER, R. B. 1989. BIOSYS-1. A computer program for the analysis of allelic variation in population genetics and biochemical systematics. Illinois Natural History Survey, Urbana, IL.

TSURUSAK1, N. 1986. Parthenogenesis and geographic variation of sex ratio in two species of Leiobunum (Arachnida, Opiliones). Zool. Sci., 3, 517-532.

UZZELL, T. M. 1970. Meiotic mechanisms of naturally occurring unisexual vertebrates. Am. Nat., 104, 433-445.

VRIJENHOEK, R. C. 1984. The evolution of clonal diversity in Poeciliopsis. In: Turner, B. J.(ed.), Evolutionary Genetics of Fishes. Plenum Press, New York, pp. 399-429.

WAGNER, K. J. 1985. Ecological genetics of Daphnia pulex in Oneida Lake, New York Ph.D. thesis. Cornell University.

WEIDER, L. J., BEATON, M. J. AND HEBERT, P. D. N. 1987. Clonal diversity in high-Arctic populations of Daphnia pulex, a polyploid apomictic complex. Evolution, 41, 1335-1346.

WEIDER, L. J. AND HEBERT, P. D. N. 1987. Microgeographic genetic heterogeneity of melanic Daphnia pulex at a low Arctic site. Heredity, 58, 391-399.

williams, G. C. 1975. Sex and Evolution. Princeton University Press, Princeton.

WILSON, C. C. AND HEBERT, P. D. N. 1992. The maintenance of taxon diversity in an asexual assemblage: an experimental analysis. Ecology, 73, 1462-1472.

WRIGHT, s. 1978. Evolution and Genetics of Populations. Vol. 4. Variability Within and Among Natural Populations. University of Chicago Press, Chicago. 